\title{
Managing patients who express racist views
}

\author{
Paula Baraitser
}

\section{Introduction}

As health professionals it is important that we do not judge our patients, yet we have an obligation to ensure that none of our colleagues are subject to discrimination on the grounds of their ethnicity. Occasionally these two obligations conflict. A practice nurse, ethicist, equal opportunities lawyer and senior National Health Service (NHS) human resources manager give us their opinions on the best way to handle this situation.

\section{Clinical scenario}

You are a junior doctor working in a family planning clinic. A patient of yours needs referral to one of several senior doctors who work in your organisation for a complicated intrauterine device fitting. You recommend a colleague who has expertise in this field and the patient agrees to be referred. However, when you mention the name of the doctor, the patient realises she might be from an ethnic minority and requests a referral to someone else. What should you do?

\section{The pane}

Four professionals (detailed in Box 1) were invited to discuss what they would have done.

Box 1: Invited discussants for the clinical scenario

- Senior nurse working in general practice

- Ethicist

- Employment rights lawyer

- Senior NHS human resources manager

\section{Senior nurse working in general practice}

I have been in this position frequently, often from asylum seekers rather than the indigenous population. I handle this by saying that in the UK we live in a multicultural society and ask if the patient had considered they are making racist comments (often they have not thought of it that way). I would explain it is not acceptable to 'choose' who provides care based on race in the same way that as clinicians we do not discriminate against or choose our patients. Usually that works. If the patient continues to make racist comments about staff, I record this in the records, explain the services available (as before) and end the consultation. For this scenario the family planning clinic will be covered by the primary care trust (PCT) policy on racial harassment and bullying.

\section{Ethicist}

In Good Medical Practice, ${ }^{1}$ the General Medical Council (GMC) tells us the treatment we provide or arrange must be based on our clinical judgement of a patient's needs and the likely effectiveness of the treatment. We must not allow our own views about the patient's "lifestyle, culture, beliefs, race, colour, gender, sexuality, disability, age or social or

\section{J Fam Plann Reprod Health Care 2006; 32(1): 47-48}

\section{Lambeth and Southwark Modernisation Programme, London, UK \\ Paula Baraitser, MD, MFFP, Specialist Registrar in Public Health Medicine}

Correspondence to: Dr Paula Baraitser, Lambeth and Southwark Modernisation Programme, Masters House, 4 Dugard Way, London SE11 4TH, UK. E-mail: Paulab@smithg3.demon.co.uk economic status" to prejudice the treatment we provide or arrange.

These guidelines make it quite clear that the junior doctor in the scenario should refer the patient for specialist treatment if that is deemed to be in her best interests. However, the question remains as to whether the doctor should take a stance against the patient's seemingly racist views. Should the doctor tackle the patient directly about them? And who should the patient be referred to? The original specialist? Or should the junior doctor comply with the patient's wishes, and refer her to someone else?

It may be helpful to consider that doctors are often asked by patients to make referrals to particular people, or to avoid certain hospitals or individuals. The reasons for these requests may appear valid and appropriate to the referring doctor, or they may not, but it would be unusual to try and dissuade a patient from their preference unless there were reasons why this would be disadvantageous to their health. The GMC guidelines seem to imply that the fact that a patient's preference is based on racial prejudice, or an irrational fear of a particular hospital, or an attachment to a particular doctor, should not make any difference to the referring doctor.

However, one could argue that the referring doctor has a moral obligation to tackle the patient about her views (and to protect the specialist from them). So what should she do in this situation? In attempting to answer this it is helpful to bear in mind that all practical decisions involve a value element. In other words, when we decide what to do we consider (sometimes without being aware of it) what is good or bad, what is worth trying to achieve, and what matters to us most. In this scenario the junior doctor will have to make a value judgement. What is more important to her? It could be taking a stance against racism, or following her PCT's racial harassment policy, or putting the patient's clinical needs first, or even following GMC guidelines.

If we consider the GMC's Duties of a Doctor, ${ }^{1}$ in particular:

- make the care of your patient your first concern;

- treat every patient politely and considerately;

- listen to patients and respect their views;

- respect the rights of patients to be fully involved in decisions about their care;

- make sure that your personal beliefs do not prejudice your patients' care;

then they do seem to imply that a doctor should not directly tackle the patient on, for example, racist views, and should respect the patient's right to choose which doctor they are referred to.

Whatever decision the doctor's values lead her to she should have made an attempt to get to the bottom of the patient's views before condemning them. Perhaps the patient has had a bad experience in the past involving a doctor with a similar sounding name who she couldn't understand properly. Simple reassurance might, then, defuse the situation. After all, there is a world of difference between exploring the patient's views and condemning them outright, especially if this affects the quality of their treatment. The former is good medical practice whereas the latter is not.

\section{Employment rights lawyer}

I would first ask why the patient has an objection to the ethnic minority doctor. If it turns out, as is likely, that the 
objections are based on simple prejudice rather than anything else then I would discuss the matter further with the patient and explain that referrals are not made on the basis of the doctor's ethnic origin but on the basis of the doctor's experience, specialist training, and so on. If the patient is still unhappy then I would refuse to make the referral to their doctor of choice but would explain that (depending on my seniority) I would need to raise it with my manager/colleague. I would then raise the issue with the appropriate hospital consultant/manager and would hope that they back my decision as it is entirely inappropriate and racially discriminatory for someone to refuse an appointment with an ethnic minority doctor. There will be hospital/surgery policies about this and I would also point these out to the patient.

Of course there may be instances where a patient may have appropriate and legitimate reasons for seeking an appointment with a doctor on the basis of gender/race/religion, for example, a devout Muslim or Christian woman may feel more comfortable being examined by a female doctor. Where possible we ought to try and meet a patient's needs in such circumstances.

Finally, in the described scenario, if the patient's request for an alternative doctor is accepted, then it would leave the hospital/trust open to a race discrimination claim by the ethnic minority doctor if she/he found out.

\section{Senior NHS human resources manager}

All employers have a duty of care to protect their staff from any form of discrimination, both direct and indirect, by other staff members or, in the case of the NHS, by patients.

While we can apply disciplinary sanctions or arrange for retraining for staff, we cannot take such direct action against patients. However, that does not mean that nothing should be done. In the present scenario, the junior doctor should check that there has been no misunderstanding and that the patient is asking not to be referred to the senior doctor simply because her name makes it likely that she is of a particular ethnic origin. The junior doctor should question this, as we cannot determine an individual's ethnicity by their name alone. The fact that the senior doctor is the expert in this field should be reiterated.

If the patient is adamant that she does not wish to be seen by the senior doctor because of her ethnicity, the junior doctor should point out that the NHS does not tolerate racist attitudes and that under the circumstances it would be appropriate to refer her to another senior colleague - but only to protect the original senior doctor, not to bow to the patient's prejudices. Knowing the views of the patient, it would not be appropriate to expose the senior doctor to them. The senior colleague who then takes the referral should be told informally that the reason that she/he has been asked to see this patient is because of the patient's racist attitude and the duty of care to a colleague.

The junior doctor should also mention this episode to the family planning clinic manager, as the problem could arise again in the patient's dealings with other members of staff, including nursing and administrative colleagues.

\section{Discussion}

Whereas we should not allow our views of patients' beliefs to prejudice the treatment we provide, we cannot accept racial harassment of our colleagues. The current GMC document, Good Medical Practice, ${ }^{1}$ advises doctors to respect their patients' views. The new GMC document, Good Medical Practice: A Draft for Consultation, ${ }^{2}$ is out for public consultation and includes a statement that "you must not allow your views about patients' ... beliefs ... to adversely affect your professional relationship with them". 2 The Nursing and Midwifery Council code of professional conduct states that: "You are personally accountable for ensuring that that you promote and respect the interests and dignity of patients and clients irrespective of gender, age, race, ability, sexuality, economic status, lifestyle, culture and religious or political beliefs". 3 The guidance from these two professional organisations raise questions about what constitutes a political belief and whether some beliefs should be acknowledged by professional organisations as unacceptable.

\section{Acknowledgements}

The author would like to thank the panel members for their input. A listing of the individual panel members who have contributed to the Clinical Conundrum section of the Journal is published annually.

References

1 General Medical Council (GMC). Good Medical Practice. London, UK: GMC, 2001. http://www.gmc-uk.org/guidance/good_medical_ practice/index.asp [Accessed 25 October 2005]

2 General Medical Council (GMC). Good Medical Practice: A Draft for Consultation. London, UK: GMC, 2005. http:// http://www.gmcuk.org/GMP_Consultation/documents/Good_Medical_Practice.pdf [Accessed 25 October 2005].

3 Nursing and Midwifery Council (NMC). The NMC Code of Professional Conduct: Standards for Conduct Performance and Ethics. London, UK: NCM, 2004. http://www.nmc-uk.org/ (w5x5una2n1uyns55ciun3g55)/aDisplayDocument.aspx?DocumentI $\mathrm{D}=201$ [Accessed 31 October 2005].

\section{Book Review}

"Six Hundred Miseries" the Seventeenth Century Womb: Book 15 of 'The Practice of Physick' by Lazare Riviere, translated by Nicholas Culpeper. JL Burton (ed.). London, UK RCOG Press, 2005. ISBN: 1-904752-13-6. Price: £24.95. Pages: 213 (paperback)

As soon as my review copy of this gorgeous little hardback arrived, colleagues kept picking it up, dipping into it, and asking to borrow it. [NB. This, other reviewers will agree, is a rare occurrence.]

Burton's preface, biographical notes on Riviere, and his concise and very readable introduction 'Humours and herbs in the 17th century' put the medicine of the period into context, and include some excellent reproductions of fascinatingly detailed engravings of the gruesome-looking practices of the day.

The book itself, Of Women's Diseases, All Englished by Nicholas Culpeper, Physician and
Astrologer, consists of 24 chapters about common gynaecological conditions, some of which are easily recognisable ("Of the falling down of the womb" needs no translation, although some of the remedies seem a little extreme) and some less so " Of mortification and blasting of the womb" refers to gangrenous conditions)

Contraception is not specifically mentioned, and Burton outlines in his introduction that it was not a preoccupation of the day. "Of barrenness" merits its own chapter, outlining the prerequisites for conception, which of course are that "the woman in her genital embracements should conveniently receive the man's sperm, she should retain it for a reasonable time, she should preserve it in her womb, she should provide fitting materials to form the embryo (blood and nutrients)" which is spot on. The description of aged virgins' genital parts and why they are unable to "easily admit a man's yard" is not for the fainthearted. The description of moist, hot and dry distempers as causes of infertility seem to describe women with various modern metabolic disorders (although "excessive carnal conjunction" is no longer considered a risk factor for infertility on its own)

There's an intriguing glossary of the herbs, animal products and minerals used by Riviere and his contemporaries, including many that will be familiar, such as Agnus Castus, sage and St John's Wort, with notes on 17 th century and modern uses. Interestingly, on the same page as the ISBN number is a small print disclaimer: "The remedies . have never been tested for safety ... Riviere's remedies and treatments as described in this book should not be used and are only of historical interest". Disappointing. I was desperate to use the "leaves of lettuce, willow tree, water lilies, vine tree, purslain and pennywort, flowers of violets, water-lilies and roses" bath soak for the next case of womb madness (nymphomania) I see in the gynae clinic.

Reviewed by Pauline McGough, MRCOG, MFFP Subspecialty Registrar in Sexual and Reproductive Health, Glasgow, UK 